\title{
DISORDERED SMALL DEFECT CLUSTERS IN SILICON
}

\author{
E. Žąsinas and J.V. Vaitkus \\ Institute of Applied Research, Vilnius University, Sauletekio 9, LT-10222 Vilnius, Lithuania \\ E-mail: ernestas.zasinas@ff.vu.lt
}

Received 28 September 2015; revised 23 November 2015; accepted 15 December 2015

\begin{abstract}
The ionizing radiation induced disordered defect clusters and their relaxation in silicon were simulated by the density functional method. It was found that a non-relaxed disordered cluster gives rise to a great number of localized states having their energy levels within the semiconductor forbidden band gap. After the relaxation, however, the density of these states significantly decreases leaving only several relatively shallow donor and acceptor state levels that may contribute to trapping of free carriers and shrinkage of an effective band gap.
\end{abstract}

Keywords: radiation clusters, disordered semiconductor, local levels

PACS: $61.72 . J-, 29.40 . \mathrm{Wk}, 61.80 . \mathrm{Az}, 71.15 . \mathrm{Mb}$

\section{Introduction}

The microscopic defects induced by high energy particle radiation affect the performance of radiation detectors and semiconductor devices degrading their functional qualities such as leakage current, depletion voltage at $\mathrm{p}-\mathrm{n}$ junctions, and the lifetime of charge carriers [1]. Many of defects are the point type lattice defects well characterized both by experimental techniques and theoretical methods. Another type of defects, usually called cluster or extended defects, are comprised of disordered regions of material resulted from a multiple interaction of material atoms with a high energy particle within its track. This type of defects still lacks the full theoretical model although they exhibit their self plentifully in experimental studies. The first and simplest model suggested by Gossick [2] represents disordered regions as a sphere charged by free carriers trapped within a cluster. The model limits itself to a simple analysis of the electrostatic problem describing the distribution of electric field within and nearby the cluster. Further insight into the atomic structure within a cluster is usually achieved by means of Monte-Carlo based methods: the Stopping and Range of Ions in Matter (SRIM), Transport of Ions in Matter (TRIM) [3], Non Ionizing Energy Loss (NIEL) [4] and molecular dynamics [5] simulations.
Microscopic parameters necessary as input in these calculation methods are usually evaluated from experimental data, quantum mechanical ab initio calculations or are just simply guessed.

Density Functional Theory (DFT) simulations based on quantum mechanics were successfully applied for the studies of small size clusters formed from several point defects - vacancies $\left(\mathrm{V}_{n}\right.$ is the cluster of $n$ vacancies [6]), self-interstitials $\left(\mathrm{I}_{n}^{n}\right.$ is the cluster of $n$ self-interstitials [ []]), one or few Frenkel pairs [8] and various combinations of vacancies, interstitial and substitute atoms, for example, $\mathrm{VO}, \mathrm{CO}, \mathrm{VOH}$, etc. (a widely accepted list of radiation defects with references therein is given in [9]). Such small complexes of point defects, mentioned here as examples, extend themselves over the region of few adjacent lattice cells. Despite their size, all these defects, however, are treated within the frame of the point defect model: they have one or few discrete energy levels in the semiconductor energy band gap, and various spectroscopy and transport experimental data are well fitted when these defects are given the values for the free carrier capture and scattering cross-sections similar to the point defect ones [9, 10].

The first (and the single so far) attempt to simulate larger defect clusters in silicon containing up to 50 randomly displaced atoms within the amorphous region of $\sim 1 \mathrm{~nm}$ in diameter by the DFT method was 
reported in [1]]. The main result of these calculations was the presence of the localized states within the cluster of both the donor and acceptor types with the corresponding energy levels in the forbidden energy gap. It was emphasized that these states are not of a point defect type but rather are the part of the ensemble of the cluster states which have their wave functions localized within the whole cluster.

In this work we have performed similar DFT studies of disordered clusters in a silicon crystal. Contrary to the approach done in [11], where the relaxation of the disordered cluster was simulated by a molecular dynamics annealing procedure with empirically defined inter atomic forces, the simulation of the relaxation in this work is done by applying molecular dynamics where atomic forces have been calculated by the DFT method. Relaxation of the atoms driven by empirical forces could lead to the states with incorrectly restored inter atomic covalent bonds and to the existence of artifact states. Therefore the purpose of our simulation was to check whether the localized states within the relaxed amorphous regions would still exist and how the number of states changed during the relaxation. The method of calculations and the obtained results are presented in the following section.

\section{Electron states in the disordered defect cluster}

Electron states originating from the defect cluster are calculated within the DFT approach. This is done with the help of the quantum chemistry software package ORCA [12]. This program is designed for the simulations of molecules, therefore the crystal under interest must be presented as a huge molecule containing a finite cluster of a crystal piece with the broken covalent bonds saturated by the hydrogen atoms. The cluster of $165 \mathrm{Si}$ atoms with additional $100 \mathrm{H}$ atoms allocated along the dissected tetrahedral bond directions was chosen for consideration. The simulation setup was the following. The simplified Resolution of Identity (RI) approach of DFT integral calculations was chosen to speed up the simulation where lots of atomic structure relaxation steps were under interest. The price of speed up was the possible loss of accuracy which, however, was not necessary for our purpose as we were interested only in a qualitative picture of electron Density of States (DOS) but not in the exact positions of energy levels. The calculations were performed within the split valence wave functions basis sets SVP and SV/J and using the Becke and Perdew [13] exchange-correlation potential BP86 (acronyms ac- cording to the ORCA manual). At first, the cluster with no defects was modeled to find the optimal relaxed $\mathrm{Si}-\mathrm{Si}$ and $\mathrm{Si}-\mathrm{H}$ bond lengths and the electron DOS corresponding to the clean crystal. The relaxation of structures was done to meet the $0.02 \mathrm{eV} / \AA$ tolerance for the maximal atomic force. For the described cluster and the chosen DFT calculation setup the obtained values of bonds in the relaxed structure are $2.38 \AA(\mathrm{Si}-\mathrm{Si})$ and $1.51 \AA(\mathrm{Si}-\mathrm{H})$, and the semiconductor forbidden band gap is $2.3 \mathrm{eV}$. Then the number of disordered cluster structures is prepared for simulation. The disordered cluster is created by randomly displacing atoms from their lattice positions. Atoms were displaced by no more than half of the $\mathrm{Si}-\mathrm{Si}$ bond length. In this work only 17 atoms are taken to form an amorphous region - one has chosen a central atom, its four nearest neighbours and twelve next-nearest neighbours. A smaller than in [11] number of atoms in the cluster was necessary to be able to run time consuming DFT molecular dynamics structure relaxations. We have calculated DOS for 25 randomly created different clusters and have run cluster relaxation for 10 of them. The example of the considered disordered non-relaxed cluster is shown in Fig. 1.a), and in Fig. 1(b) its relaxed structure is shown. And in Fig. $2(a, b)$ there are the main objects of our interest the electron DOS for the structures given in Fig. 1.

The main feature of the DOS picture of the nonrelaxed defect cluster (Fig. 2(a)) is the presence of dense energy level sets in the semiconductor band gap with the highest occupied level located near the middle of the band gap. This feature was common for all considered 25 randomly created clusters. Simulated relaxation of these clusters has led either to the full restoration of the crystalline structure (in 19 cases) or (in 6 cases) to the clusters with only fewer atoms remaining in disordered positions. The average formation energy of the obtained relaxed cluster defects is $3.4 \mathrm{eV}$. As a result of relaxation, the number of localized states was significantly reduced as seen from one of the typical examples (Fig. 2(b)) of the relaxed structures. Note that the energy levels of the localized states that remained after relaxation are closer to the conduction and valence bands and there were no energy levels observed around the middle of the energy gap. This result differs from the state spectra of large clusters reported in [11] where the deep level states are statistically present in relaxed cluster structures both with the relaxation being simulated by means of the classical molecular dynamics method and checked with the DFT relaxation method. The obvious reason of such a difference is the smaller size of clusters studied in our work. As 
(a)

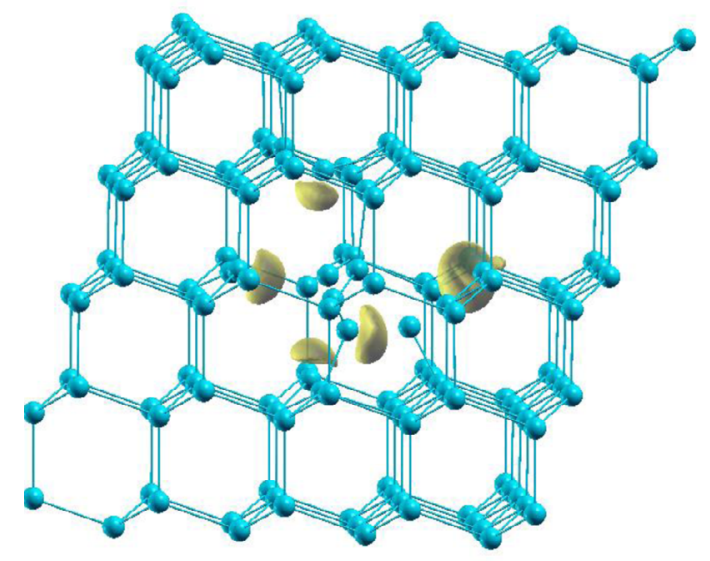

(b)

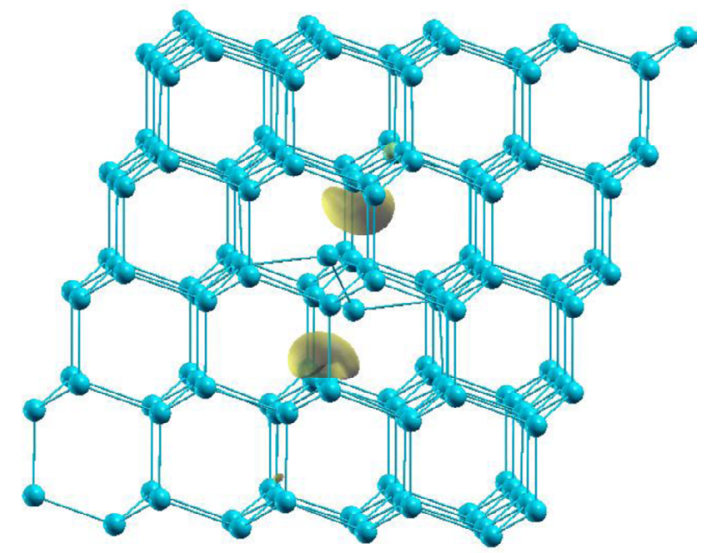

Fig. 1. An example of the initial (a) and relaxed (b) atomic structure in the defect cluster along with the LUMO orbital isosurfaces drawn at 0.33 of their maximum value. The rods between atoms are drawn if the distance between them is less than $2.2 R_{\text {cov }}$ where $R_{\text {cov }}=1.16 \AA$ is a silicium covalent radius. Structures are visualized with the xCrysden program [14].

one can see from the example of the relaxed structure in Fig. 1 (b), the crystalline ordering around the defect is nearly restored and the remaining couple of two interstitial atoms accompanied with two vacancies may be considered as a point defect extending beyond one lattice cell rather than the cluster due to the discrete energy levels of states in this particular defect. A closer inspection of the defect shown in Fig. 1(b) suggests it to be similar to the fourfold coordinated silicon point defect described in [8] and proposed as a building block of an amorphous structure.

Given that a large number of separate cluster defects even of this small size are present in the crys- tal, the shallow donor and acceptor levels provided by each cluster (see DOS at $-5.2 \mathrm{eV}$ and $-3.6 \mathrm{eV}$ in Fig. 2(b)) should statistically lead to an effective band gap narrowing which exhibits itself as decaying band tails in various spectroscopy experiments carried out on polycrystalline samples [15, 16] and silicon containing extended defects [17]. As for the $-3.8 \mathrm{eV}$ level state which appears to be the Lowest Unoccupied Molecular Orbital (LUMO) in our chosen cluster example, it originates itself from the dangling bonds represented by the wave function isosurface drawn in Fig. 1(b). The number of such states with the energy levels close to the conductivity band can capture electrons and create the negative charged
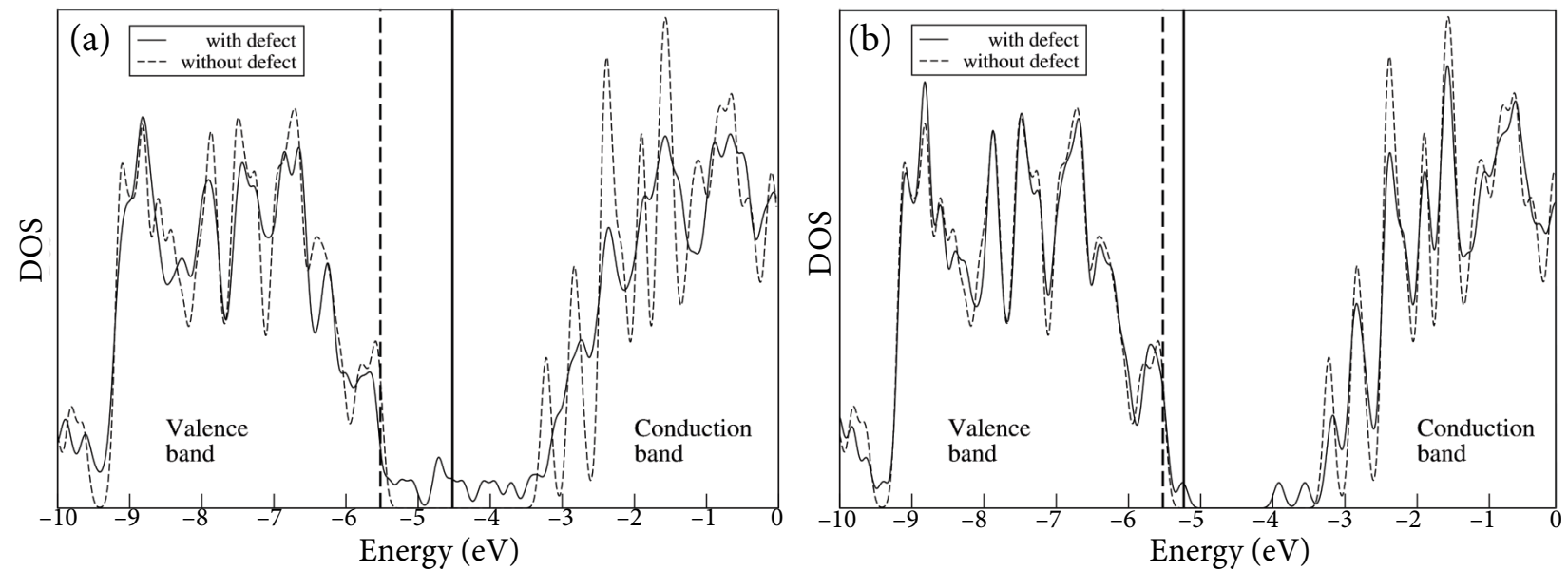

Fig. 2. Electron DOS for the non-relaxed (a) and relaxed (b) defect clusters shown in Fig. 1. In both figures the DOS of defect clusters (solid lines) are compared with the DOS of a clean crystal (dashed lines). The vertical lines of corresponding styles indicate the energy positions of the highest occupied orbital levels. 
space region around itself in the doped n-type semiconductor. This charged region may affect the motion of free charge carriers and thus affect the transport of free carries in the semiconductor.

\section{Conclusions}

The modeling of a small disordered region reveals the appearance of rather shallow traps for the electrons that can influence the trapping and transport of free carriers and this trapping will be sensitive to the doping and electric field in the semiconductor.

It could be proposed that the obtained change of density of states in the bands can also appear around the larger clusters if the disordered regions will remain after the lattice relaxation, and it will introduce a possibility of reduction of the effective band gap around the clusters that may contribute to the capture of both signs of carriers by the clusters.

\section{Acknowledgements}

This study was performed as a part of CERN RD50 collaboration and funded by the European Social Fund under the Global Grant Measure Project VP13.1-ŠMM-07-K-03-010.

\section{References}

[1] G. Lutz, Semiconductor Radiation Detectors. Device Physics (Springer, 2007), http://dx.doi. org/10.1007/978-3-540-71679-2

[2] B.R. Gossick, Disordered regions in semiconductors bombarded by fast neutrons, J. Appl. Phys. 30, 12141217 (1959), http://dx.doi.org/10.1063/1.1735295

[3] J.F. Ziegler, Beam interactions with materials and atoms, Nucl. Instrum. Methods B 219-220, 1027-1036 (2004), http://dx.doi.org/10.1016/j. nimb.2004.01.208

[4] M. Huhtinen, Simulation of non-ionising energy loss and defect formation in silicon, Nucl. Instrum. Methods A 491, 194-215 (2002), http://dx.doi. org/10.1016/S0168-9002(02)01227-5

[5] M. Aboy, I. Santos, L. Pelaz, L.A. Marqués, and P. López, Modeling of defects, dopant diffusion and clustering in silicon, J. Comput. Electron. 13, 40-58 (2014), http://dx.doi.org/10.1007/s10825013-0512-5

[6] J.L. Hastings, S.K. Estreicher, and P.A. Fedders, Vacancy aggregates in silicon, Phys. Rev. B 56,
10215-10220 (1997), http://dx.doi.org/10.1103/ PhysRevB.56.10215

[7] M.P. Chichkine, M.M. De Souza, and E.M.S. Narayanan, Growth of precursors in silicon using pseudopotential calculations, Phys. Rev. Lett. 88, $085501 \quad$ (2002), http://dx.doi.org/10.1103/ PhysRevLett.88.085501

[8] S. Goedecker, T. Deutsch, and L. Billard, A fourfold coordinated point defect in silicon, Phys. Rev. Lett. 88, 235501 (2002), http://dx.doi.org/10.1103/ PhysRevLett.88.235501

[9] M. Moll, Radiation Damage in Silicon Particle Detectors - Microscopic Defects and Macroscopic Properties, Ph. D. Thesis, DESY-THESIS-1999-040 (Universität Hamburg, December 1999).

[10] M. Moll, Development of radiation hard sensors for very high luminosity colliders - CERNRD50 project, Nucl. Instrum. Methods A 511, 97-105 (2003), http://dx.doi.org/10.1016/S01689002(03)01772-8

[11] E. Holmström, K. Nordlund, and M. Hakala, Amorphous defect clusters of pure $\mathrm{Si}$ and type inversion in Si detectors, Phys. Rev. B 82, 104111 (2010), http://dx.doi.org/10.1103/PhysRevB.82.104111

[12]F. Neese, The ORCA program system, WIREs Comput. Mol. Sci. 2, 73-78 (2012), http://dx.doi. org/10.1002/wcms.81

[13]A.D. Becke, A multicenter numerical integration scheme for polyatomic molecules, I. Chem. Phys. 88, 2547-2553 (1988), http://dx.doi. org/10.1063/1.454033

[14] A. Kokalj, Computer graphics and graphical user interfaces as tools in simulations of matter at the atomic scale, Comp. Mater. Sci. 28, 155-168 (2003), http://dx.doi.org/10.1016/S0927-0256(03)00104-6

[15]J. Werner and M. Peisl, Exponential band tails in polycrystalline semiconductor films, Phys. Rev. B 31, 6881-6885 (1985), http://dx.doi.org/10.1103/ PhysRevB.31.6881

[16]F. Finger, J. Muller, C. Malten, R. Carius, and $\mathrm{H}$. Wagner, Electronic properties of microcrystalline silicon investigated by electron spin resonance and transport measurements, J. Non-Cryst. Solids 266-269, 511-518 (2000), http://dx.doi. org/10.1016/S0022-3093(99)00802-9

[17] H. Wenman and B. Monemar, Strain induced intrinsic quantum wells as the origin of broad band photoluminescence in silicon containing extended defects, Mater. Res. Soc. Symp. Proc. 163, 257-260 (1990). 


\title{
NEDIDELI NETVARKŪS DEFEKTŲ KLASTERIAI SILICYJE
}

\author{
E. Žąsinas, J.V. Vaitkus
}

Vilniaus universiteto Taikomujų mokslu institutas, Vilnius, Lietuva

\section{Santrauka}

Jonizuojančioji spinduliuotè sukuria netvarkias defektų sankaupas. Nedidelès sankaupos ir sukurtos sankaupos modeliuotos tankio funkcionalo metodu silicio kristale. Gauta, kad nerelaksavusios sankaupos sukuria daug lokalizuotu būsenu draustineje juostoje. Pasibaigus relaksacijai didžioji dalis šių būsenų sumažèja ir lieka santykinai seklių donorinès ir akceptorinès prigimties lygmenų, kurie gali daryti ịtaką krūvininkų prilipimui bei mažinti efektinị draustinès juostos plotị. 